\title{
Use of a real-time virtual patient simulation for interprofessional distance education: A pilot study
}

\author{
Paul Burmeister ${ }^{1}$, Gabrielle Isaacs ${ }^{1}$, Bronwen Griffiths ${ }^{1}$, Lanxinning $\mathrm{Mo}^{1}$, Jordan $\mathrm{Chin}^{1}$, Cate McCall ${ }^{2}$, \\ Stephen Duffull ${ }^{1}$ (it) \\ ${ }^{1}$ School of Pharmacy, University of Otago, Dunedin, New Zealand \\ ${ }^{2}$ Centre for Postgraduate Nursing Studies, University of Otago, Christchurch, New Zealand
}

\author{
Keywords \\ Interprofessional education \\ Nursing student \\ Pharmacy student \\ Real-time simulation \\ Virtual patient \\ Correspondence \\ Stephen Duffull \\ School of Pharmacy \\ University of Otago \\ Dunedin \\ New Zealand \\ stephen.duffull@otago.ac.nz
}

\begin{abstract}
Objective: To evaluate the use of cloud-based virtual patients as a tool for engagement in interprofessional distance education (IPDE). Methods: Five pairs of final-year pharmacy and final-year nursing students interacted with an autonomous, real-time, cloud-based virtual patient (VP). They were debriefed after completion of their case and completed a questionnaire on the relevance of the VP to core IPE competencies. Results: The virtual patient approach was considered to be able to cover 25 of the 39 core IPE competencies. From a thematic analysis, there was evidence of students learning from, with, and about each other. Conclusions: The use of cloud-based autonomous VPs could be a successful tool for IPE.
\end{abstract}

\section{Introduction}

The logistic challenges of interprofessional education (IPE) are significant, with most IPE occurring in synchronous settings, i.e. at a time when the different team members are in the same place at the same time (Bridges et al., 2011). The authors have recently piloted the use of a real-time, cloud-based, virtual patient (VP) simulation using SimPHARM (Duffull \& Peterson, 2020) for asynchronous IPE with positive findings (Duffull et al., 2020). In this report, they will describe the expansion of this approach to pilot virtual patients for interprofessional distance education (IPDE), in which all participants were at different geographical locations.

\section{Methods}

\section{Participants}

Participants were final year Bachelor of Pharmacy (BPharm) and Master of Nursing Science (MNSc) students. Five participants from each professional programme were recruited. The pharmacy student participants had previously used SimPHARM in years 2, 3,4 of their professional programme as part of their training. Nursing student participants had not used SimPHARM previously. The pharmacy and nursing students did not know each other prior to the study and were not co-located during the study. The study occurred during the COVID-19 lockdown, and all interactions between and within researchers and participants took place through the online video platform Zoom.

\section{Study design}

The study was performed in three parts. In Part 1, nursing students attended an initial SimPHARM training session and, later, the pharmacy and nursing students were provided time to socialise on a zoom meeting and then completed a multiplayer practice case together synchronously. The same VP (Theo Anderson; summary 
in Appendix A) was used for both situations. Part 2 involved teams of pharmacy and nursing students caring for a VP (Amelia Thompson; summary in Appendix B). In Part 3, participants were invited to attend a synchronous debrief session by Zoom and complete a questionnaire (full results are shown in Appendix C). The questionnaire consisted of 25 questions based on a 5-point Likert scale. Students were asked to rate their ability to achieve core IPE competencies (Anon., 2016) via interaction with their VP. Of the 39 core competencies, 14 were excluded as they were deemed impossible to meet by interacting with a VP (e.g., respecting the dignity and privacy of patients). In addition, SimPHARM log files for each team were reviewed. This study was approved by the University of Otago Human Ethics Committee (23 April 2020, D20/103).

Qualitative data were collected during the debriefing. All quotes were transcribed, collated, and formatted in Excel. A thematic analysis was performed for evidence of IPE qualities. All participants were assigned an ID number (pharmacy students: P1, P2, ...; nursing students: N1, N2, ...).

\section{Results}

Of the 39 core competencies, 25 were rated by the students as being moderately or highly amenable to IPDE using a VP. Of note, RR7, CC1, CC5, and TT2 were rated as being moderately amenable by pharmacy students and highly amenable by nursing students (who rated all elements highly amenable). See Appendix $C$ for details.

The log files from SimPHARM showed that each IPE team enacted between a median of 4 treatment decisions (range: $2-7$ ), resulting in the prescription of new medicines, de-prescribing, and changing the dose of existing medicines. These decisions were predicated on a median of 33 lab tests (2-84) and communicated with 19 (9-54) clinical notes, of which 7 (5-14) were considered to be interactive (asynchronous discussion).

The qualitative data were reviewed for evidence of an IPE theme that might reflect the use of the distance VP approach. Three IPE themes were identified.

(1) Students learning with each other:

"We decided things together. We would bounce ideas back and forth, then come to a decision, and then prescribe" (P5) and "In working cases together, it [SimPHARM] was a good tool" (P1).
(2) Students learning from each other

Comments from students included "Active conversation with my partner was good as we learnt from each other" (N2) and "I learnt stuff [from my pharmacy partner] in a different way that's helpful-[concepts] made much more sense when [my] partner explained it" (N5).

\section{(3) Students learning about each other}

One nursing student reflected upon differences between their pharmacy partner and themselves: "I noticed a difference in the types of questions asked between my partner and I" (N5), and a pharmacy student: "[SimPHARM] helped me to understand the role of the nursing students and how their knowledge differed from mine, and how we could work together to improve patient care" (P5).

\section{Discussion}

The results of this study illustrate the practicality of IPDE using a cloud-based VP approach. Students rated their IPE experience well and indicated that they felt the VP approach could potentially cover 25 of the 39 core competencies in part or entirely, including eight communication competencies. While all activities were conducted at a distance, the initial socialisation and debriefs were both synchronously run by a virtual meeting platform. Given that the VP generated by SimPHARM is autonomous, the student's interaction with the VP did not require the presence of a tutor, and students could complete the case in their own time and location. An additional benefit of an autonomous VP approach is that students can 'experiment' safely without negative educational consequences from their decisions (de Visser et al., 2011).

The thematic analysis revealed evidence of the three principles of IPE (WHO, 2013), with both pharmacy and nursing students indicating that they learnt from, with, and about each other through this experience.

\section{Conclusions}

Based on user experiences, SimPHARM could fill a gap in IPE education. The VP simulation may provide a platform for many of the IPE core competencies required for IPE programmes. 


\section{Acknowledgements}

The authors thank the Pharmacy and Nursing students for taking part in this study.

\section{References}

Anon. Interprofessional Education Collaborative (2016). Core Competencies for Interprofessional Collaborative Practice: Report of an Expert Panel. Washington, DC. Retrieved from: https://ipecollaborative.org/uploads/IPECCore-Competencies.pdf

Bridges, D.R., Davidson, R.A., Odegard, P.S., Maki, I.V., \& Tomkowiak, J. (2011). Interprofessional collaboration: three best practice models of interprofessional education. Medical Education Online. 16;

https://doi.org/10.3402/meo.v16i0.6035 de Visser, H., Watson, M.O., Salvado, O., \& Passenger, J.D. (2011). Progress in virtual reality simulators for surgical training and certification. The Medical Journal of Australia. 194(S4):S38-S40. https://doi.org/10.5694/j.13265377.2011.tb02942.x

Duffull, S.B., \& Peterson, A.K. (2020). Students' perceptions of playing a serious game intended to enhance therapeutic decision-making in a pharmacy curriculum. Currents in Pharmacy Teaching and Learning. 12(11):1348-1353. https://doi.org/10.1016/j.cptl.2020.05.011

Duffull, S., Peterson, A., Chai, B., Cho, F., Opoku, J., Sissing, T., Smith, D., Tongskul, T., \& Wilby K. (2020). Exploring a scalable real-time simulation for interprofessional education in pharmacy and medicine. MedEdPublish. https://doi.org/10.15694/mep.2020.000240.1

WHO (World Health Organization). (2013). Framework for Action on Interprofessional Education \& Collaborative Practice. [March 4, 2013].

https://www.who.int/hrh/resources/framework_action/en/ 


\section{Appendices}

\section{Appendix A: Case summary - Theo Anderson}

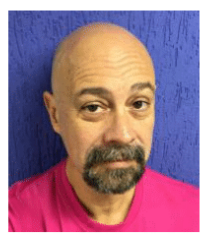

\section{SimPHARM Case Description}

Case Level: Early Learning

Case Run: Single visit, 1 hour

Patient: Theo Anderson

\section{Patient Description:}

\section{Introduction to Theo:}

Mr Anderson is admitted under your care with a simple fracture of the tibia with evidence of deformity in the local area. The medical team wish you to chart some analgesia.

Gender: Male

Weight: $176 \mathrm{lbs} . / 80 \mathrm{~kg}$

Height: $5^{\prime} 11^{\prime \prime} / 180 \mathrm{~cm}$

Age: 60

\section{Case Details:}

Theo has no pre-existing conditions. He arrives with the paramedical team currently feeling little if any pain. Theo had received a sedative prior to your arrival as he was extremely agitated. He is just waking up from this and his pain is returning. The pain will return over the next half-an-hour.

\section{Pathologies:}

\begin{tabular}{|l|l|l|l|c|}
\hline Condition & Severity & Occurrence & Duration & Probability \\
\hline $\begin{array}{l}\text { Simple fracture of the } \\
\text { tibia }\end{array}$ & Severe pain & $\begin{array}{l}\text { Acute-maximum } \\
\text { pain occurs if } \\
\text { untreated at 40 } \\
\text { minutes into case. }\end{array}$ & $\begin{array}{l}\text { Duration of } \\
\text { case }\end{array}$ & $100 \%$ \\
\hline
\end{tabular}

\section{Pre-existing Medication:}

Nil

Availability of drugs and laboratory investigations:

Only three drugs are available in this case (paracetamol / acetaminophen, naproxen and morphine ). All investigations are available for students.

\section{Debrief notes}

This is a 1 hour case. Almost no lab tests can be ordered and returned within an hour which means the student is faced with the prospect of making a decision in the absence of all information that could (in theory) be known. They have only 3 choices.

A choice of paracetamol alone would need to be justified by the student and when the student reflects to identify that this did not provide adequate or fast enough pain relief.

A choice of naproxen while perhaps logical for this type of pain is far to slow in onset to have any significant effects.

The only choice therefore that can work is morphine. Note students will see side effects emerge which will vary between students so this is an important debrief point for the class. 


\section{Appendix B: Case summary - Amelia Thompson}

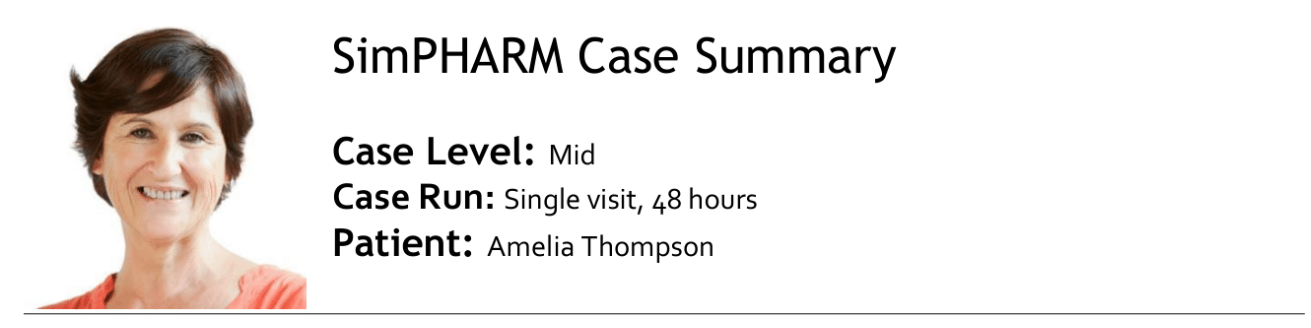

\section{Patient Description:}

\section{Introduction to Amelia:}

Amelia has been referred to the student for management of her hypertension.

\section{Gender: Female}

Weight: $173 \mathrm{lbs} . / 78 \mathrm{~kg}$

Height: $5^{\prime} 5^{\prime \prime} / 165 \mathrm{~cm}$

Age: 52

\section{Case Details:}

Amelia has mild-moderate essential hypertension. She has been initiated on a starting dose of cilazapril. This does has not been titrated and her hypertension is current not under control. She has a history of asthma and osteoarthritis. This case mixes silent disease with symptomatic diseases and tests the student's ability to prioritise. The relatively short time frame for the case will limit what the student can achieve so target setting for BP will need to be focused on what they would anticipate seeing at 48 hours treatment.

Amelia is quite resistant to paracetamol / acetaminophen for her $(L)$ knee OA. This will require the student to think about the benefits:risks of the use of NSAIDs in relation to her cardiovascular risks and BP control.

\section{Pathologies:}

\begin{tabular}{|l|l|l|l|c|}
\hline Condition & Severity & Occurrence & Duration & Probability \\
\hline Hypertension & Mild-moderate & Pre-existing & Whole case & $100 \%$ \\
\hline Osteoarthritis (L) knee & Moderate to severe & $\begin{array}{l}\text { Chronic ongoing } \\
\text { pain and } \\
\text { symptoms. }\end{array}$ & Whole case & $100 \%$ \\
\hline Asthma & Mild & $\begin{array}{l}\text { Acute symptoms } \\
\text { occur in the } \\
\text { morning of day 1 }\end{array}$ & $\begin{array}{l}\text { Lasts 1-2 } \\
\text { hours (if } \\
\text { untreated) }\end{array}$ & $100 \%$ \\
\hline Asthma & Mild & $\begin{array}{l}\text { Acute symptoms } \\
\text { occur in the } \\
\text { morning of day 2 }\end{array}$ & $\begin{array}{l}\text { Lasts 1-2 } \\
\text { hours (if } \\
\text { untreated) }\end{array}$ & $75 \%$ \\
\hline
\end{tabular}

\section{Pre-existing Medication:}

Cilazapril $1 \mathrm{mg}$ daily

Paracetamol [acetaminophen] $1000 \mathrm{mg}$ every four times per day

Salbutamol inhaler (100 mcg/puff) prn

\section{Availability of drugs and laboratory investigations:}

All drugs and investigations are available for students.

\section{Debrief notes}

There is nothing overtly complicated in this case. However the mix of acute and chronic and silent and symptomatic conditions will test the student's cognitive load. An important discussion point for the debrief is to be self aware of their decision making process. In particular some students may agressively treat the hypertension when in fact Amelia may have had this for more than 5 years.

In addition, the student's treatment choice and reasoning for the treatment of Amelia's OA should be examined. 


\section{Appendix C: Responses to Questionnaire 2 - IPE core competencies survey}

The overall responses to the core competencies are provided below.

There are 39 core interprofessional education competencies (Anon., 2016), of which 14 were excluded from the analysis as they were deemed impractical to be met using a virtual patient interaction (e.g. respecting the dignity of patients). The results for the remaining 25 competencies are represented as the median score by each profession (i.e. per pharmacy or nursing). Each student completed a 5 -point Likert scale for each of the 25 competencies. These scores were then pooled across students from the same profession and also across all students (Aggregate Score). The medians of these scores were then summarised as Low (a median score $\leq 2.5$ ), medium (a median score $>2.5 \&<3.5$ ), and high (a median score $\geq 3.5$ ).

\begin{tabular}{|c|c|c|c|c|}
\hline Question & Core Competencies & Pharmacy & Nursing & Aggregate score \\
\hline VE1 & $\begin{array}{l}\text { Place interests of patients at centre of interprofessional health } \\
\text { care delivery and population health programs and policies, with } \\
\text { the goal of promoting health and health equity across the life } \\
\text { span. }\end{array}$ & High & High & High \\
\hline VE5 & $\begin{array}{l}\text { Work in co-operation with those who provide care, and others } \\
\text { who contribute to or support the delivery of prevention and } \\
\text { health services and programs. }\end{array}$ & High & High & High \\
\hline VE6 & Develop a trusting relationship with other team members. & High & High & High \\
\hline VE9 & $\begin{array}{l}\text { Act with honesty and integrity in relationships with other team } \\
\text { members. }\end{array}$ & High & High & High \\
\hline RR2 & Recognise one's limitations in skills, knowledge, and abilities. & High & High & High \\
\hline RR3 & $\begin{array}{l}\text { Engage diverse professionals who complement one's own } \\
\text { professional expertise, as well as associated resources, to develop } \\
\text { strategies to meet specific health and healthcare needs of } \\
\text { patients and populations. }\end{array}$ & High & High & High \\
\hline RR5 & $\begin{array}{l}\text { Use the full scope of knowledge, skills, and abilities of } \\
\text { professionals from health and other fields to provide care that is } \\
\text { safe, timely, efficient, effective, and equitable. }\end{array}$ & High & High & High \\
\hline RR7 & $\begin{array}{l}\text { Forge interdependent relationships with other professions within } \\
\text { and outside of the health system to improve care and advance } \\
\text { learning. }\end{array}$ & Medium & High & High \\
\hline RR9 & $\begin{array}{l}\text { Use unique and complementary abilities of all members of the } \\
\text { team to optimise health and patient care. }\end{array}$ & High & High & High \\
\hline RR10 & $\begin{array}{l}\text { Describe how professionals in health and other fields can } \\
\text { collaborate and integrate clinical care and public health } \\
\text { interventions to optimize population health. }\end{array}$ & Medium & High & High \\
\hline CC1 & $\begin{array}{l}\text { Choose effective communication tools and techniques, including } \\
\text { information systems and communication technologies, to } \\
\text { facilitate discussions and interactions that enhance team function. }\end{array}$ & High & High & High \\
\hline $\mathrm{CC} 2$ & $\begin{array}{l}\text { Communicate information with health team members in a form } \\
\text { that is understandable, avoiding discipline-specific terminology } \\
\text { when possible. }\end{array}$ & High & High & High \\
\hline CC3 & $\begin{array}{l}\text { Express one's knowledge and opinions to team members involved } \\
\text { in patient care and population health improvement with } \\
\text { confidence, clarity, and respect, working to ensure common } \\
\text { understanding of information, treatment, care decisions, and } \\
\text { population health programs and policies. }\end{array}$ & High & High & High \\
\hline $\mathrm{CC} 4$ & $\begin{array}{l}\text { Listen actively and encourage ideas and opinions of other team } \\
\text { members. }\end{array}$ & High & High & High \\
\hline CC5 & $\begin{array}{l}\text { Give timely, sensitive, instructive feedback to others about their } \\
\text { performance on the team, responding respectfully as a team } \\
\text { member to feedback from others. }\end{array}$ & Medium & High & High \\
\hline CC6 & $\begin{array}{l}\text { Use respectful language appropriate for a given difficult situation, } \\
\text { crucial conversation, or conflict. }\end{array}$ & High & High & High \\
\hline $\mathrm{CC7}$ & $\begin{array}{l}\text { Recognise how one's own uniqueness (experience level, expertise, } \\
\text { culture, power, and hierarchy within the health team) contributes } \\
\text { to effective communication, conflict resolution, and positive } \\
\text { interprofessional working relationships. }\end{array}$ & High & High & High \\
\hline
\end{tabular}




\begin{tabular}{|c|c|c|c|c|}
\hline Question & Core Competencies & Pharmacy & Nursing & Aggregate score \\
\hline CC8 & $\begin{array}{l}\text { Communicate the importance of teamwork in patient-centred } \\
\text { care and population health programs and policies. }\end{array}$ & High & High & High \\
\hline TT2 & $\begin{array}{l}\text { Develop consensus on the ethical principles to guide all aspects of } \\
\text { teamwork. }\end{array}$ & Medium & High & High \\
\hline TT3 & $\begin{array}{l}\text { Engage health and other professionals in shared patient-centred } \\
\text { and population-focused problem solving. }\end{array}$ & High & High & High \\
\hline TT4 & $\begin{array}{l}\text { Integrate the knowledge and experience of health and other } \\
\text { professions to inform health and care decisions, while respecting } \\
\text { patient and community values and priorities/preferences for care. }\end{array}$ & High & High & High \\
\hline TT5 & $\begin{array}{l}\text { Apply leadership practices that support collaborative practice and } \\
\text { team effectiveness. }\end{array}$ & High & High & High \\
\hline TT6 & $\begin{array}{l}\text { Engage self and others to constructively manage disagreements } \\
\text { about values, roles, goals, and actions that arise among health } \\
\text { and other professionals and with patients, families, and } \\
\text { community members. }\end{array}$ & High & High & High \\
\hline TT7 & $\begin{array}{l}\text { Share accountability with other professions, patients, and } \\
\text { communities for outcomes relevant to prevention and health } \\
\text { care. }\end{array}$ & High & High & High \\
\hline TT8 & $\begin{array}{l}\text { Reflect on individual and team performance for individual, as well } \\
\text { as team, performance improvement. }\end{array}$ & High & High & High \\
\hline
\end{tabular}

Questionnaire - IPE core competencies. VE = Values/Ethics, RR = Roles $/$ Responsibilities, CC = Interprofessional Communication, $\mathrm{TT}=$ Teams \& Teamwork. 